\title{
OS INVASORES: AS AMEAÇAS QUE REPRESENTAM AS MIGRAÇÕES SUBSAARIANA NA ESPANHA E HAITIANA NO BRASIL
}

\author{
Antônio Tadeu Ribeiro de Oliveira ${ }^{1}$
}

\begin{abstract}
Este artigo apresenta os processos que envolvem a migração subsaariana para Espanha e a haitiana para o Brasil, passando pelos fatores que impulsionam os deslocamentos, as rotas migratórias utilizadas, a inserção social e laboral desses migrantes e o momento das políticas migratórias em cada um dos países de destino, ressaltando as semelhanças e algumas diferenças em cada um desses processos. O objetivo é demonstrar que longe de se constituírem numa ameaça invasora, mais bem são vítimas de um sistema que produz exclusão e exploração, que nos casos de subsaarianos e haitianos se amplifica pelos componentes da discriminação e racismo.
\end{abstract}

Palavras-chave: migração internacional, emigração subsaariana, emigração haitiana, discriminação.

\section{Introdução}

Este artigo pretende abordar os processos que envolvem a imigração subsaariana na Espanha, tratando, em particular, daquela retida em Celta e Melilla, e da imigração haitiana na fronteira norte brasileira. Além de enfrentar barreiras ao ingresso nos países de destino, devido à política migratória vigente ou à falta de uma - especificamente no caso brasileiro -, tanto uma diáspora quanto outra, com uma certa constância, têm chegado de forma sensacionalista aos noticiários nacionais e internacionais, que buscam fazer acreditar à opinião pública que esses imigrantes são uma ameaça e uma fonte de problemas para os países receptores.

Agrava a situação o fato de serem negros, virem de países pobres, chegarem aos milhares e com o aspecto que a viagem empreendida, repleta de achaques, abusos e violência, os permitiu. Isto por si só já é combustível suficiente para alimentar preconceitos e racismos, explícitos ou não, nas sociedades de destino.

1 Instituto Brasileiro de Geografia e Estatística (IBGE), Rio de Janeiro, RJ, Brasil. 
A forma como esses meios de comunicação noticiam a chegada de subsaarianos e haitianos reflete a visão de mundo da elite dominante e de certa parcela da sociedade, crédulos que esses indivíduos, desprovidos dos meios de reprodução em seus lugares de origem, estão verdadeiramente invadindo os seus países, sendo a medida adequada para enfrentar "o problema" mandá-los de volta, seja para onde for, de forma a manter a situação sob controle e longe de suas fronteiras. Ao proporem enfrentar a questão pela ótica da segurança, nada mais fazem do que expressar o modo preconceituoso e, em alguns casos, racista de tratar a migração, sem ao menos parar para refletir sobre a real dimensão do fenômeno, que é bem inferior ao da entrada através de aeroportos, portos e outras áreas de fronteiras de imigrantes irregulares brancos². Essa forma de perceber a migração segue alimentando a indústria de coyotes, expondo os migrantes a mais violência, construindo cercas de arame farpado, no caso da Espanha, e os depósitos de gente como os observados em Ceuta, Melilla e Brasiléia.

No intuito de buscar entender essa questão a partir de uma outra perspectiva, tentaremos tratar os fatores que impulsionaram os fluxos, as estratégias adotadas para chegarem aos lugares de destino e o modo como se inserem nesses lugares, de modo a traçar uma dimensão mais real do fenômeno vis a vis as respectivas políticas migratórias nos países receptores, além de apontar possíveis soluções para o enfrentamento da migração oriunda dos países em desenvolvimento.

\section{Fatores que impulsionam a emigração: exclusão e falta de oportunidades}

O primeiro aspecto que fica evidente, ao olharmos de onde vêm os fluxos que seguem para as fronteiras espanholas com Marrocos, é a profunda desigualdade econômica e social entre as áreas de origem e de destino, por mais que persista a crise na economia europeia. Essas pessoas, que tentam ingressar no território europeu, vêm, sobretudo, de Mali, Senegal, Congo, Costa do Marfim, República dos Camarões, Gâmbia, Guiné, Guiné Bissau, Chade, República Centro-Africana e Nigéria, quer dizer, de países que ainda não ingressaram

2 No Brasil, o teto das estimativas aponta para a entrada de 40 mil haitianos a partir de 2010 . Ao confrontar esses números com os dados do $\mathrm{CNIg} / \mathrm{CGlg}$, que para o mesmo período sinalizam com o ingresso de cerca de 15 mil autorizações permanentes, e com o número de trabalhadores estrangeiros no mercado informal do Censo Demográfico 2010, nota-se, ao menos, um equilíbrio entre o volume do coletivo haitiano com o dos imigrantes não negros. Isto para não utilizar a estimativa da CNBB que sinalizava, em 2008, com 600 mil imigrantes irregulares no país. No caso da Espanha, a ONG Cruzando Fronteras estima em aproximadamente 4 mil o número de imigrantes nas fronteiras de Ceuta e Melilla, contra uma estimativa de Recaño e Domingo que assinalam que $47 \%$ dos cerca de 1 milhão de estrangeiros estão em situação irregular no país. 
de fato no circuito internacional do capital, estando, portanto, excluídos da sociedade do consumo vigente nos dias atuais.

Esses países de origem encontram-se em estágios de desenvolvimento bastante defasados em relação às demais nações. No último relatório do Programa das Nações Unidas para o Desenvolvimento apareciam classificados como de baixo desenvolvimento humano, com um IDH igual ou menor que 0.534. Isto, por outro lado, implica que, na maioria ou integralidade dos casos, as respectivas transições demográficas ainda estejam, em sua etapa primeira, com níveis de mortalidade ainda altos e indicadores elevados de natalidade. De acordo com a projeções da Nações Unidas, para o ano de 2012, a esperança de vida ao nascer era de 54,3 anos, a taxa de mortalidade infantil ao redor de $72 \%$ e taxas de fecundidade total superiores a 5,6 filhos por mulher. Isto implica que as populações sejam compostas por aproximadamente $40 \%$ de crianças, com idade média de cerca de 20 anos e experimentem razões de dependência muito altas. Tudo isso coloca uma pressão muito forte sobre os respectivos mercados de trabalho, que, por não estarem desenvolvidos internamente e muito menos integrados à economia global, não são capazes de responder à demanda por empregos. Vivem com um PIB per capita inferior a 2 mil dólares anuais, com serviços de educação e saúde de baixa qualidade, com redes de saneamento básico inadequadas e sem infraestrutura que permita impulsionar o desenvolvimento econômico, além do que, em boa parte dos países, as guerras e os conflitos internos, étnicos ou políticos, são uma constante.

$\mathrm{Na}$ perspectiva global, o continente africano funciona na divisão internacional do trabalho como fornecedor de matéria prima, em especial, riquezas minerais e alimentos. Recentemente governos africanos colocaram à venda suas terras para que fossem adquiridas por governos e empresas europeias e asiáticas. Uma verdadeira neocolonização, nas palavras do Prof. Mbuyi Kabunda, professor de Relações Internacionais da Universidade Autônoma Madri.

Vivenciando essa realidade, ao olharem para o outro continente e sabendo que a renda média dos seus habitantes é infinitamente superior e que por mais simples que seja o trabalho conseguido seus rendimentos podem quintuplicar em relação aos percebidos nos lugares de origem, que poderão usufruir de serviços de proteção social melhores, que terão ao seu alcance uma melhor educação e ante a possibilidade de escaparem de um contínuo estado de beligerância, é impossível que a migração não seja percebida como estratégia fundamental para a sua sobrevivência e reprodução, mesmo que tudo isso faça parte de uma

Cf. El otro lado de la valla. Direção: Meritxell Aranda et alii. Produção: Atras Media Television. Madrid, 2014. 57:35 min, son. color. 
construção imaginária que de fato possa nunca vir a se realizar. Em síntese, estão colocadas ante um quadro onde razões estruturais os impelem a emigrar.

Em relação aos haitianos, após quatro anos do terremoto, que provocou uma das maiores catástrofes no país, matando cerca de 220.000 pessoas e deixando 1,5 milhão de desabrigados, pouco há mudado. O país que tinha uma das piores situações econômica das Américas viu ainda mais agravado esse quadro. O Haiti convive com instabilidade nos sistemas políticos e de segurança; com crise de desabastecimento; escassez de água potável e falta de infraestrutura de saneamento básico. Apenas $5 \%$ da sua cobertura florestal está intacta e não tem opção de geração de energia, uma vez que a madeira extraída foi utilizada na produção de carvão. Situação que além de ser grave do ponto de vista econômico, deixa o país ainda mais vulnerável a fenômenos naturais como furações e terremotos, como os observados recentemente.

Os serviços públicos praticamente não existem, a rede privada detém cerca de $85 \%$ dos hospitais e das escolas. Devido a sua geografia, apenas $12 \%$ das terras são agricultáveis e a taxa de desemprego beira os $80 \%$. Num cenário desses, a emigração surge para os haitianos como estratégia mais imediata para a garantia da sua reprodução e de suas famílias. Tradicionalmente, os haitianos buscavam como lugar de destino, entre outros, Estados Unidos, República Dominicana, Canadá, França, Venezuela, Cuba e outros países das Antilhas. O Brasil só mais recentemente surge como destino dessa migração.

Silva ${ }^{4}$ assinala que para além do terremoto que devastou o Haiti, a emigração de haitianos, não só para o Brasil, é resultado do processo global de reprodução do capital, que transformou aquele país num exportador de matérias primas e mão-de-obra.

Franck Seguy em sua tese de doutoramento aponta que o Haiti passa por um processo de "recolonização", que antecede a ocorrência do terremoto de 2010, com um plano do capital internacional de explorar a mão de obra barata e especializada no setor têxtil. Justifica sua afirmação em dois pontos principais de argumentação: i) ao identificar que os principais investimentos no país são nas zonas francas de produção, que não se encontram nas áreas mais afetadas pelo terremoto; e ii) que o papel do Haiti na divisão internacional do trabalho é contribuir com força de trabalho barata ${ }^{5}$.

Entre outros fatores, três principais têm contribuído para a entrada do Brasil na rota migratória dos haitianos: i) o fato de, desde 2004, estar presente no Haiti, liderando uma força de paz das Nações Unidas, denominada Missão

\footnotetext{
4 SILVA, Sidney Antonio da. Brazil, a new Eldorado for Immigrants?: The Case of Haitians and the Brazilian Immigration Policy.

5 ORSI, Carlos. "Ajuda internacional ao Haiti é 'grande mentira', defende tese".
} 
das Nações Unidas para a Estabilização do Haiti - MINUSTAH (sigla em francês), que, em linhas gerais, deveria ${ }^{6}$ contribuir para restaurar o Estado de direito e restabelecer a segurança pública naquele país; ii) a forma como o Governo brasileiro passa ao exterior a imagem de país em ascensão e hospitaleiro. Chegou inclusive a levar a seleção brasileira de futebol para jogar um amistoso com o selecionado haitiano, com direito à carreata e tudo o mais. Como diz Martins ${ }^{7}$, "foram iludidos por uma propaganda internacional de prosperidade que de fato aqui não houve nem há na escala capaz de absorver excedentes populacionais de outros países"; e iii) o recrudescimento no fechamento das fronteiras nos países desenvolvidos, como França e EUA, ademais das hostilidades sofridas na República Dominicana.

Se o que foi mencionado acima são os fatores explicativos para justificar a emigração haitiana e colocar o Brasil como destino desses fluxos, como explicar que tentem entrar de forma irregular?

Desde que iniciou, em 2010, um maior afluxo de haitianos ao país, o Brasil passou a estabelecer cotas de entradas anuais, que iam aumento à medida que os fluxos se tornavam mais volumosos, até chegarmos a um determinado ponto no ano de 2013 de não mais limitarmos o ingresso desses migrantes. Aparentemente, tinha-se encontrado uma solução para uma questão que havia se tornado extremamente dramática pela exposição a abusos e violências, falta de assistência e condições de saúde e higiene para essa população. Ocorre que a burocracia e a falta de estrutura dos consulados brasileiros no Haiti e depois nos outros países de origem da migração haitiana tornaram a emissão dos vistos um processo lento e complicado, levando a população emigrante do Haiti incluir em suas estratégias a entrada de forma irregular no Brasil.

Observa-se que os fatores estruturais motivadores da emigração estão fortemente presentes em todos os países de origem: exclusão, exploração da força de trabalho, falta de infraestrutura básica e de serviços e novos processos de "recolonização" são marcas comuns.

Recorrendo à metáfora de Bauman ${ }^{8}$, os migrantes subsaarianos e haitianos são os resíduos produzidos globalmente por um modelo de acumulação excludente, no qual aqueles que não fazem parte do circuito do consumo ficam de fora, devendo ser descartados. A questão imediatamente colocada é: onde deve ser vertedouro?

$\overline{6} \mathrm{O}$ verbo utilizado na condicional em função das controvérsias sobre o verdadeiro papel desempenhado pelas forças brasileiras no Haiti. Há quem afirme que estamos para facilitadores de uma "recolonização" do que para prestadores de ajuda humanitária, mas essas questões não estão no escopo deste trabalho.

7 MARTINS, José de Souza. "Sem lenço e sem documento".

8 BAUMAN, Zygmunt. Vidas desperdiciadas: La modernidad y sus parias. 
Éante um quadro desse, onde impera a novos processos de "recolonização", exploração, falta de oportunidades e condições de vida, que "nossos bravos invasores africanos e haitianos decidem deixar seus países para "atacar", se submetendo a intermediação de coyotes e aos mais diversos tipos de abusos e violações praticados por policiais corruptos nos países de trânsito. "Com esse grau de organização e motivação não há como não temer uma ameaça invasora dessa magnitude!!!".

\section{As rotas utilizadas: abusos e violências}

Muitos dos subsaarianos utilizam como rota atravessar milhares de quilômetros pelo deserto para chegarem ao Norte da África, na fronteira entre Marrocos e Espanha, e aí atingirem os únicos pontos de entrada terrestre ao território europeu que ficam em Ceuta e Melilla. Aqueles com pouco mais de recursos se arriscam na travessia pelo mar ou escondidos dentro de veículos. Carregam poucos pertences e muitas incertezas. Sofrem toda sorte de abusos praticados pelas máfias que fazem o tráfico de pessoas, morrem ao longo da travessia, suportam o rigor e as armadilhas impostas pelas intempéries climáticas, tudo isso em busca de um último refúgio para superarem o obstáculo final: as cercas colocadas pelo governo espanhol e financiadas pela União Europeia.

Ainda no Marrocos, antes de tentar saltar as cercas, a partir do Monte Gurugú, essas pessoas, que chegam esgotadas, com doenças respiratórias e de pele, após viagens que duram em média seis meses, recebem ajuda de grupos católicos que, com o apoio da Organização Médicos Sem Fronteiras, atuam no sentido de orientar o acesso aos serviços de saúde marroquinos, oferecem acesso à linha telefônica 24 horas, ajudam com materiais de primeira necessidade e na sensibilização para o tratamento de doenças e prevenção daquelas sexualmente transmissíveis. Além disso, durante a permanência no Monte Gurugú, que pode levar meses, recebem ajuda da população local, que fornecem algum alimento para cozinharem.

Do outro lado da fronteira, na tentativa de manter longe os imigrantes, a Espanha mantém um sistema de cerca de alta tecnologia ao redor dos enclaves. São cercas em duas camadas, com 12 quilômetros de extensão e seis metros de altura, em Melilla, e 8,6 quilômetros em Ceuta. O arame farpado e as lanças pontiagudas colocados no alto da cerca haviam sido retirados pelo governo socialista ante os reclamos de várias ONGs, em especial a Anistia Internacional. Contudo, em novembro 2013, com o incremento nas tentativas de entradas, o atual governo conservador resolveu recolocar o arame farpado, como uma medida dissuasória, nas palavras do Ministro do Interior. 
Os meios de comunicação e os governos marroquino e espanhol disseminam estimativas absurdas que apontam para cifras na ordem de 40 mil africanos querendo entrar na Espanha. Cabe destacar que esse volume é infinitamente superior ao da maior onda de entrada de subsaarianos ocorrida em 2005, quando cerca de 6 mil pessoas ingressaram em território espanhol e outras 3 mil esperavam pela mesma oportunidade ainda no Marrocos. Por outro lado, no ano de 2006, que foi o ano recorde de chegadas de imigrantes em embarcações na Espanha, havia 10 mil pessoas esperando na Mauritânia para ir às Canárias.

Portanto, cabe questionar a quem e com quais objetivos interessa fazer uma estimativa tão exagerada e completamente fora da realidade? A não ser para estigmatizar e marginalizar ainda mais a esses imigrantes, além de aproveitar a oportunidade para arrancar mais recursos para serem aplicados na segurança, ou para outros fins, como no caso do Marrocos, que utiliza os imigrantes como moeda de troca, como forma de obter mais recursos financeiros para reprimir as tentativas de entrada em solo espanhol. Deve-se assinalar, ademais, que o agrupamento de um grande número de pessoas para empreenderem o intento simultaneamente em muito é facilitado pelas autoridades de Marrocos. E há quem especule que do outro lado da cerca também é de interesse do governo da Espanha mostrar esses eventos a fim de obter mais ajuda da União Europeia.

Nos últimos meses, com a intensificação dos fluxos e o aumento nas tentativas de entradas algumas mortes e vários episódios de violência, praticados por policiais espanhóis e marroquinos, foram observados na região de fronteira. Ao recrudescimento da repressão, os migrantes passaram a responder com estratégias organizadas para lograrem cruzar a fronteira. Reúnem-se no monte Gurugú em grupos grandes e tentam escalar as cercas em vários pontos diferentes ao mesmo tempo, de modo a dispersar a atenção das forças de segurança espanholas e marroquinas. Deve-se ressaltar que as forças policiais marroquinas não respeitam os limites territoriais entre os dois países e, em muitas ocasiões, entram no espaço espanhol para reprimir e deportar os imigrantes. Só mesmo quando conseguem chegar aos abrigos instalados no lado da Espanha é que podem considerar que a tentativa teve sucesso, fato que é comemorado entusiasticamente por aqueles que lá já se encontravam e por quem recém conseguiu chegar.

Essas pessoas chegam aos abrigos com marcas dos ferimentos ocorridos ao longo da viagem, pelo espancamento sofrido pelas polícias dos dois lados da fronteira e pelas feridas produzidas pela cerca. Muitos necessitam de atendimento médico e alguns chegam a morrer. 
Estimativas apontam que mais aproximadamente 20 mil migrantes morreram ao tentar atravessar da África para o território europeu nos últimos 25 anos$^{9}$. Nicolás Castellano, um jornalista, que por ser originário das Ilhas Canárias e ter passado boa parte da sua vida assistindo às inúmeras tentativas dos imigrantes africanos para ingressar em solo europeu, passou a investigar o fenômeno migratório. Ele assinala que "não é possível que no século XXI as pessoas morram por cruzar uma fronteira"10.

No Brasil, frente às dificuldades e obstáculos, mencionados anteriormente, para obtenção do visto de entrada no Brasil, uma parcela expressiva de haitianos passou a adotar uma rota entre os dois países dominada por coyotes. Esses migrantes seguem para a República Dominicana, onde embarcam em voo da Copa Airlines até o Equador e, de lá, seguem de ônibus, utilizando a Autopista Interoceânica, em viagens que chegam a durar uma semana, para o Peru e a fronteira do Acre ou Tabatinga, que são pontos mais vulneráveis, o que facilita o trabalho dos atravessadores. De acordo com uma pesquisa liderada pelos Professores Duval Fernandes e Maria da Consolação de Castro, cerca de 2/3 da imigração haitiana seria intermediada por $\operatorname{coyotes}^{11}$.

Originalmente, a entrada de haitianos no Brasil pela fronteira norte se dava no Estado do Acre, cruzando os limites do Peru e ingressando em Brasiléia, e no Amazonas, através da Colômbia e chegando a Tabatinga. Mais recentemente, a Venezuela, que seria país pretendido como destino principal, face à crise política e econômica, passou a servir como passagem para a entrada ao Brasil através do Amazonas.

Ao adotarem a forma irregular como estratégia de ingresso mais rápido ao Brasil, essas pessoas se expõem a todo tipo de violações de direitos, como abusos sexuais, maus tratos por policiais, tortura, sequestros-relâmpago, roubos, furtos, sobretudo no Peru, que, segundo os migrantes, é o local em que a viagem é mais difícil e arriscada.

Para alcançar o Brasil, muitos desses haitianos chegam a investir 5.000 dólares com transporte, alimentação e pagamento ao coyotes, sem saber em quanto tempo ou se terão retorno da quantia gasta na empreitada migratória.

No final de 2013, os coyotes que atuam no tráfico ilegal de pessoas teriam divulgado no Haiti e República Dominicana que o Brasil fecharia a fronteira com o Peru. Isto provocou um êxodo ainda maior de haitianos para o Brasil, o que levou o governo do Acre, no início de 2014, efetivamente cogitar a possibilidade

\footnotetext{
9 "Una tragedia mediterrânea".

${ }^{10}$ CASTELLANO, Nicolás. "Não é possível que no século XXI pessoas morram por cruzar uma fronteira".

${ }^{11}$ FERNANDES, Duval; CASTRO, Maria C. G. Migração haitiana ao Brasil: diálogo bilateral.
} 
de solicitar ao Governo Federal o fechamento da fronteira com o Peru. Tratava-se de uma medida descabida, pois seria uma forma de transferir o enfrentamento da questão aos países vizinhos, que apenas são utilizados como passagem para esses imigrantes, da mesma forma que o Estado do Acre, pois o objetivo dos migrantes é alcançar as regiões do país com maior oferta de trabalho. Além disso, seria uma medida frontalmente contrária ao discurso defendido pelo Governo brasileiro em tratar a questão migratória na perspectiva das garantias dos direitos dos migrantes. Felizmente o Governo brasileiro não permitiu que fosse cometido esse grave equívoco.

A vulnerabilidade é a marca presente e comum nas rotas adotadas por esses migrantes subsaarianos e haitianos, bem como entre outros grupos, como os que tentam ingressar nos Estados Unidos e outros africanos que elegem entrar na Europa via Itália, onde se destacam, entre outras: a submissão à exploração imposta pelos coyotes; todo tipo de violências impetrado por esses mesmos coyotes e agentes de segurança nos países de trânsito e destino; riscos à saúde e integridade física, que podem inclusive levar à morte. No caso dos subsaarianos, acrescente-se as barreiras físicas, na forma de cercas, que adicionam ainda mais o componente da violência e dos danos físicos produzidos ao se tentar transpor um aparato duplo de seis metros de altura com arame farpado na extremidade superior. Espanha e a fronteira norte do Brasil também guardam em comum o fato de serem elegidas como áreas de passagens nas rotas estabelecidas, de modo que o objetivo é alcançar outros países da Europa ou, no caso brasileiro, regiões mais desenvolvidas do país.

Uma outra semelhança, pouco comentada, mas superdimensionada nos meios de comunicação e governamentais, diz respeito aos volumes desses fluxos, que em realidade são inexpressivos, quando comparados às outras entradas irregulares, o que reforça o aspecto da discriminação sofrida por subsaarianos e haitianos.

Segundo a metáfora de Bauman ${ }^{12}$ : embora os resíduos sejam produzidos em escala global, face ao vigente modelo de reprodução do capital, a solução para os vertedouros deve ser obtida localmente, pois devem ser mantidos distantes dos centros de onde foram gerados. Daí a necessidade das cercas, muros e toda sorte de expediente para mantê-los afastados.

"A logística e a estratégia para perpetrarem a invasão mostra o quão perigosos e ameaçadores são esses invasores!! "

${ }^{12}$ BAUMAN, op. cit. 


\section{A inserção nos países de destino: mais exploração e discriminação}

\subsection{A chegada ao destino}

Como já foi mencionado, os subsaarianos, que conseguem passar das cercas, chegam aos os centros de passagem, conhecidos como CETIs (Centro de Estancia Temporalde Inmigrantes), feridos pelos golpes dos policiais marroquinos e espanhóis e pelos ferimentos produzidos pela cerca de arame farpado. Nesses centros começa outro calvário, a espera pelo resultado do pedido do refúgio, que pode durar meses, num processo revestido do componente aleatório, apresentando decisões distintas para casos semelhantes.

São lugares inóspitos e abarrotados de gente, sem a menor condição de higiene e comodidade. Em Melilla, por exemplo, o centro que tem capacidade para atender 480 pessoas chegou a comportar mais de 2500 imigrantes de 30 nacionalidades diferentes, que foram alojados em barracas de campanha instaladas pela Cruz Vermelha e pelo governo espanhol. Recentemente, com a bem sucedida tentativa de entrada de quinhentos imigrantes, o Ministro do Interior, Jorge Fernández Díaz, afirmou que "a situação do CETI de Melilla tinha chegado ao limite".

No lado espanhol, grupos religiosos católicos têm buscado dar apoio aos imigrantes subsaarianos. Os bispos espanhóis afirmam que não se pode ficar apenas na denúncia, que é necessária, mas que é preciso avançar no encontro de soluções que eliminem ou minimizem o sofrimento daquelas pessoas. Por fim, emitiram um pedido específico aos escritórios diocesanos: "Na Igreja, tudo ou quase tudo é pastoral, mas com o trabalho social e de promoção que a Caritas leva avante admiravelmente, nós os convidamos a cuidarem também do serviço da fé e não somente dos serviços que brotam da fé"13.

Além dos CETIs existem os Centros de Detenção de Estrangeiros (CIEs, na sigla em espanhol) ${ }^{14}$, que é para onde são levados os imigrantes irregulares à espera da deportação. Tanto aqueles que tentaram ingressar na Espanha e não conseguiram, quanto aqueles que devido à falta de trabalho perderam a condição de regular. Nos CIEs também ficam detidos os estrangeiros que praticaram algum delito. Esses centros se transformaram em espaços de exceção, sem a menor condição de saúde ou sanitária, prática de violência e violação dos direitos dos imigrantes, tendo inclusive ocorrido mortes que ficaram sem o devido esclarecimento. O imigrante ao ingressar no CIE passa a ser identificado por um número e deixando de ser tratado pelo seu nome, num procedimento

\footnotetext{
13 "Os Bispos: Não podemos fazer somente denúncia profética, busquemos soluções para evitar a dor dos irmãos migrantes". Agenzia Fides, Madrid, 11 abril de 2014.

${ }^{14}$ Centros de Internamientos de Extranjeros (CIEs).
} 
muito similar ao utilizado nos campos de concentração. As pessoas segregadas e discriminadas nesses espaços podem ficar até 60 dias até para serem deportadas ${ }^{15}$, em total privação de liberdade, na imensa maioria dos casos, pelo simples fato de não estarem em situação regular no país. Em suma, por uma questão administrativa passam por situações ainda mais degradantes do que aqueles que cumprem pena nas prisões espanholas. No ano de 2013, quase $50 \%$ das pessoas detidas nos CIEs não foram deportadas, conforme informe do próprio governo espanhol.

Do outro lado do Oceano Atlântico, desde 2010, o número de haitianos no Brasil apresenta estimativas inexatas que variam de 20 a 40 mil pessoas. Segundo relatos de ONGs e da Pastoral do Migrantes, é comum encontrarmos entre essas pessoas gente enferma, mulheres grávidas e desacompanhadas de seus cônjuges, abaladas psicologicamente frente aos abusos sofridos ao longo da viagem.

Depois dos percalços enfrentados desde o Haiti, os que chegavam ao Acre se deparavam com uma situação na qual o abrigo destinado a eles, que existia no município de Brasiléia, para receber 300 pessoas, chegou a abrigar 1200 . Relatório do Ministério Público Federal apontou que a situação do abrigo era de completa precariedade, faltando condições mínimas de comodidade, saúde e higiene, com as pessoas vivendo em meio ao esgoto, com apenas 10 vasos, 8 chuveiros e surtos de diarreia, que chegaram a atingir 90\% dos imigrantes ali abrigados.

O Secretário de Direitos Humanos do Acre, em entrevista a um meio de comunicação, referindo-se ao aumento da entrada de haitianos no início de 2014, afirmou que "a administração do caos chegou ao limite"16. Essa situação chegou a um ponto tal de desrespeito à dignidade humana que levou ao fechamento do abrigo em Brasiléia.

Segundo o Governador do Acre, em dezembro de 2013, o Ministério da Justiça teria feito um acordo no sentido que os imigrantes não passariam mais que três dias no Estado, o que efetivamente não aconteceu. Na perspectiva de que esses imigrantes fossem acolhidos em maior volume no Estado de São Paulo e ante a forte pressão migratória, foi fechado o abrigo em Brasiléia e construído outro com a mesma capacidade na cidade de Rio Branco, aumentando drasticamente a distância a ser percorrida pelos migrantes, já exauridos pela viagem cheia de riscos e exploração. Como as coisas não evoluíram no tempo

${ }^{15}$ Em muitos casos, por falta de recursos financeiros, Espanha não consegue deportar os imigrantes detidos. Então após o período de 60 dias o imigrante é colocado e liberdade, correndo o risco de ser detido novamente.

${ }^{16}$ Cf. "Complicada a situação dos haitianos no Acre". O estrangeiro. Brasil país de imigração. Disponível em: <http://oestrangeiro.org/2014/01/16/complicada-a-situacao-dos-haitianos-no-acre/>. 
adequado, o governo do Acre, unilateralmente e de forma desrespeitosa e indigna, passou a colocar os imigrantes em ônibus e mandá-los para a cidade de São Paulo, levando a Prefeitura paulista, de forma emergencial e com apoio da Missão da Paz, entidade ligada à Igreja Católica, improvisar um abrigo para receber e acolher essas pessoas, bem como buscar inseri-las no mercado de trabalho.

Aqui cabe destacar o trabalho dos grupos religiosos no acolhimento dessas pessoas: contando com a solidariedade da sociedade e de outros imigrantes foi o principal suporte aos imigrantes, uma vez que o poder público não estava preparado para tratar a situação.

Para os imigrantes que chegaram ao Amazonas a situação apresentou-se um pouco melhor, mas não muito diferente. Ficavam empilhados em colchões manchados de suor e redes, nas dezenas de residências de passagem espalhadas por Manaus, que abrigaram, segundo cifras, também pouco precisas, pelo menos metade dos 21 mil haitianos que entraram oficialmente no Brasil.

O que se pode dizer dessa situação é que, se por um lado a entrada dos haitianos é, em alguma medida, facilitada pelo Governo Federal, faltam as condições básicas para a efetiva integração desses imigrantes à sociedade e ao mercado de trabalho no Brasil. Problema que se viu piorado com a vinda, ultimamente, de famílias inteiras o que dificulta não só o acolhimento como a mobilidade para outras cidades do país.

Uma vez que conseguem ingressar no país de forma irregular, os haitianos passam a fazer pedidos de regularização de permanência no Brasil. Esses pedidos são encaminhados diretamente ao Ministério da Justiça, que os submete à apreciação do Conselho Nacional de Imigração, que por sua vez verifica a possibilidade de concessão de visto humanitário destinado ao trabalho.

Mais uma vez, traços comuns surgem, como na questão dos abrigos, independente da vontade política do país receptor querer receber ou não essa imigração. Oficialmente, o Brasil nada teria em contra à chegada dos haitianos; já a Espanha, além do enfoque na segurança, leva a questão para o campo jurídico das relações internacionais, à medida que passa a avaliar, à luz da Convenção de Genebra, se os pedidos de refúgios se justificam ou não. O fato é que tanto num caso quanto no outro, esses indivíduos ao chegarem são colocados em locais sem a mínima condição de abrigá-los, seja do ponto de vista da simples comodidade, seja do ponto de vista sanitário.

\subsection{0 papel dos meios de comunicação}

Parte dos meios de comunicação espanhóis faz o trabalho de reverberar a visão conservadora e preconceituosa que setores da sociedade têm em relação 
à migração subsaariana. Sempre que abordam o tema o fazem de modo a amplificar a situação, caracterizando-a como uma ameaça fora de controle. As expressões empregadas remetem a situações bélicas ou a catástrofes ambientais como: invasão, infiltração, desembarque, inundação, ondas, marés, avalanches e, mais recentemente, tsunami são costumeiramente empregadas ao se noticiar a chegada de imigrantes. Desse modo, ao disseminar de forma enviesada e superestimada a questão buscam gerar no restante da sociedade uma opinião contrária à imigração.

Também no Brasil, uma parcela elitista da sociedade e os meios de comunicação, que tão bem a representa, tratam a chegada desses migrantes como uma ameaça, como se o país tivesse sendo invadido por uma horda de desocupados, baderneiros que vêm para cá para pressionar o tão combalido sistema de proteção social e o mercado de trabalho.

Esse modo de abordar o tema instiga ao menos duas perguntas: como tratar por "clandestino" alguém que tem rosto e de quem se sabe a origem, se conhecem as rotas utilizadas no deslocamento, os destinos desejados e os pontos por onde pretende entrar? A outra pergunta diz respeito ao caráter de "ameaça": onde ela efetivamente se materializa para receber esse tipo de tratamento?

Na prática essa postura da mídia busca criar no seio da sociedade um sentimento contrário aos imigrantes, à medida que dissemina preconceitos e gera discriminação, ao mesmo tempo em que reivindica/aciona que a questão seja tratada pelo viés da segurança.

\subsection{A inserção laboral}

Do ponto de vista da inserção social e laboral na Espanha, aqueles que têm o pedido de refúgio concedido ou em alguma medida conseguem escapar das forças de segurança e permanecem de forma irregular no país, passam por situações não menos degradantes do que as enfrentadas até então.

A questão do acesso à saúde, que estava assegurada, independentemente da situação do imigrante, após a reforma sanitária implantada pelo Real Decreto 16/2012, de 20 de abril, passou a gerar confusões e incertezas não só entre os imigrantes quanto entre os profissionais de saúde, dado que apenas algumas modalidades de atenção permaneceram sendo oferecidas de forma universal. O problema de acesso aos serviços de saúde se agrava sobretudo porque as regulações em cada Província são realizadas de forma autônoma e diversificada. Essa absurda decisão, que só faz aumentar os custos ao não diagnosticar doenças antes que se tornam graves e ainda expõe toda a sociedade quando doenças contagiosas não são tratadas com a devida prevenção, produz importantes 
desigualdades sociais e quebra o princípio fundamental básico dos direitos humanos que é o acesso universal à saúde.

Aos imigrantes, regulares ou não, são destinadas as ocupações menos nobres e ainda mais mal remuneradas. Os que trabalham no mercado informal são ainda mais explorados, dado que empresas/empresários se prevalecem da vulnerabilidade dessas pessoas para aumentarem seus ganhos à margem da legalidade, numa próspera economia submersa.

Esses imigrantes acabam por ser tratados como cidadãos de segunda classe, apesar de muitos possuírem boa escolaridade, tendo que se submeter, mais uma vez, a todo tipo de adversidade e exploração, numa clara atitude discriminatória por parte de empregadores e governo.

Do ponto de vista da inserção laboral dos haitianos, em grande medida, aqueles que conseguem sair de Brasiléia e de Tabatinga conseguem fazê-lo de forma precária no mercado de trabalho brasileiro, sobretudo no Centro-Sul, em atividades da construção civil, metalúrgicas, têxteis, hoteleiras e, principalmente, na agroindústria da carne, recebendo salários que variam em média de $R \$ 600$ a $R \$ 800$. São pessoas que, em muitos dos casos, têm formação de nível médio ou universitário.

Todavia, não obstante todo o sofrimento passado no percurso até o Brasil, a maioria desses imigrantes volta a sofrer novo tipo de exploração por empresários inescrupulosos, que se aproveitam da vulnerabilidade desse grupo para pagar salários abaixo do mínimo e, em alguns casos, expor o trabalhador migrante a situações análogas à escravidão.

Dois casos de flagrante de trabalho análogo ao escravo, envolvendo imigrantes haitianos, tiveram grande repercussão. O principal deles culminou no resgate de 100 haitianos que viviam em condições degradantes, numa obra da mineradora Anglo American no município mineiro de Conceição do Mato Dentro. Os trabalhadores estavam condições degradantes em alojamentos que mais lembravam as senzalas de nossa tradição escravista. A outra situação, por mais absurda que possa parecer, ocorreu num canteiro de obras da Construtora Sisan, que trabalhava para o Programa Habitacional do Governo Federal, Minha Casa Minha Vida, no município de Cuiabá, de onde foram resgatados 21 imigrantes. Há indícios que esses casos se multiplicam no país e que há violações que não chegam ao conhecimento público e das autoridades.

Como assinalado inicialmente, um dos fatores que levaram à emigração era justamente a exploração da força de trabalho. Ao chegarem aos países de destino, subsaarianos e haitianos, embora com remuneração um pouco melhor, voltam a ser explorados, sendo vítimas do trabalho precário, mal remunerado 
e em condições adversas. Servindo de mão de obra barata para o lucro de empresários oportunistas e inescrupulosos.

\subsection{A situação da política migratória na Espanha e no Brasil}

Em relação às políticas migratórias, a Espanha que até bem pouco tempo pautava suas ações no sentido de atrair e integrar os imigrantes à sociedade espanhola, com a crise econômica, e combinado com a pressão exercida pela União Europeia, passou a enxergar o tema migratório pela ótica da segurança, ao invés de seguir mirando a migração como oportunidade de desenvolvimento econômico e social, pautada pela garantia dos direitos dos migrantes. Para enfrentar os problemas gerados em Ceuta e Melilla o Governo fala mais sobre investimento em infraestruturas que estão sendo realizados para reforçar a vigilância nos perímetros fronteiriços, do que, por exemplo, reforçar a ajuda e o desenvolvimento dos países subsaarianos. A União Europeia ficou de aportar, ainda em 2014, cerca de 10 milhões de euros para sejam investidos no reforço da segurança em Ceuta e Melilla. Recentemente, as cercas foram estendidas para um perímetro de 26 quilômetros, com a colocação de um tipo de malha anti-subida ${ }^{17}$.

No sentido contrário das boas práticas, o Governo espanhol diminuiu seu orçamento para cooperação com a África a valores tão irrisórios, que mais bem se deve dizer que não há aporte à cooperação com aquele continente ${ }^{18}$. Da mesma maneira, com a crise econômica instaurada a partir de 2008, os recursos disponibilizados pela União Europeia para este tipo de cooperação internacional também foram reduzidos, o que mostra a forma absolutamente negligente como a questão vem sendo tratada seja por parte da Espanha, seja por parte da UE, seja por parte das Nações Unidas.

O jornalista Nicolás Castellano, ao abordar o assunto numa entrevista, colocou a questão da seguinte forma:

Cada vez que se produz um aumento no número de pessoas que tentam entrar na Europa ou na Espanha ou cada vez que se produz um fato como este [a morte de 15 pessoas] sempre os políticos de todas as vertentes, ou seja, deste partido ou de outro, sempre anunciam um reforço nas medidas de segurança, falam de luta contra a imigração, este tipo de linguagem. Agora se fala em reforçar a cerca outra vez. É absolutamente absurdo ${ }^{19}$.

A situação migratória na fronteira sul da Espanha e da UE ${ }^{20}$ precisa ser encarada de forma integrada, baseada nos princípios do desenvolvimento econômico e social e na garantia dos direitos humanos dos imigrantes. Tratar

\footnotetext{
17 RAMOS, Toñy. "Fernández Díaz dice en Mellilla que a España no se entra por la ventana".

18 VALENCIANO, Elena. "Nunca habrá una valla suficientemente alta".

${ }^{19}$ CASTELLANO, op. cit.

${ }^{20}$ Há também questões migratórias tão ou mais graves na Itália, Malta e Grécia.
} 
a questão pela ótica da segurança apenas irá provocar mais mortos e feridos e enriquecer ainda mais os cofres dos traficantes de pessoas, que sempre surgem com uma nova rota ou um novo ponto de entrada, expondo ainda mais os imigrantes, como no caso recente, quando passaram a utilizar a Bulgária ao invés da Grécia como porta de entrada para a Europa.

No Brasil, no momento em que se escreve este artigo, a falta de uma política clara para a migração, seja para nossos nacionais fora do país, seja para os imigrantes que por aqui aportam, faz com que a Secretaria de Assunto Estratégico (SAE) ocupe espaço na mídia, na academia e na sociedade em geral, falando em atrair 3\% de imigrantes qualificados; o Conselho Nacional de Migração (CNIg/MTE) passe boa parte do tempo "apagando incêndios", regulando o problema a partir de Resoluções Normativas e ampliando as cotas para os haitianos, até chegar ao ponto de eliminá-las, passando a aceitar a todos; e a Secretaria Nacional de Justiça (SNJ/MJ) tente emplacar uma nova lei de migração fundamentada nas garantias e direitos dos migrantes, falando até mesmo em criar uma "Agência Reguladora" que passasse a tratar das questões da migração de forma centralizada, ao contrário do que se observa nos dias de hoje.

Enquanto isso, o país segue com uma norma que remonta aos tempos da ditadura militar, quando o imigrante era percebido como uma ameaça e, portanto, deveria ser tratado como uma questão de segurança nacional. Enfrentando uma disputa para ver se avança no sentido de entender as migrações na perspectiva dos direitos e garantias dos migrantes ou permanece encarando a imigração na ótica da classificação, seleção e localização ${ }^{21}$.

Subsaarianos e haitianos sofrem nos lugares de destino com políticas migratórias hostis, baseadas no princípio da segurança, no caso da Espanha, ou com a falta de políticas claras, como no caso do Brasil. Tanto numa situação quanto na outra, fica evidente a falta de garantias aos direitos mais elementares desses imigrantes.

\section{Comentários finais}

Martuscelli22 compara a situação dos migrantes africanos que tentam ingressar na Itália, através de Lampedusa, com a situação dos haitianos que tentam entrar no Brasil, uma vez que violações e mortes e fronteiras fechadas marcam os trajetos entre o lugar de origem e de destino. Esses episódios ocorrem não só nos limites de Brasil, Espanha, Itália, Grécia ou Malta, mas também nos países de trânsito como no Peru, Marrocos, Líbia, Argélia e Tunísia onde traficantes e forças de segurança praticam as piores barbaridades e abusos, ou

\footnotetext{
${ }^{21}$ VAINER, Carlos. Estado e Migrações no Brasil - anotações para uma história das políticas migratórias.

22 MARTUSCELLI, Patrícia N. "A distância entre Lampedusa e Brasil".
} 
seja, a situação se repete em outros espaços sempre associada àqueles que utilizam a migração como estratégia de sobrevivência e reprodução e àqueles que produzem pobreza, desigualdade e exclusão pelo mundo e agora fecham suas fronteiras, e até mesmos as rotas utilizadas pelos migrantes, para manter os resíduos produzidos bem distante, como diria Bauman ${ }^{23}$.

Enfim, os processos são muito semelhantes onde haja diásporas produzidas pela exclusão, exploração e falta de oportunidades de trabalho ou mesmo pelas guerras e conflitos étnicos, políticos ou religiosos. Por tudo que passam desde os fatores de expulsão, os riscos sofridos nos trajetos até os lugares de destino e as mais diversas vulnerabilidades a que são expostos para tentar se inserirem numa nova sociedade, longe de se constituírem numa ameaça, mais bem deviam ser vistos e recebidos como vítimas de um sistema excludente. Longe de serem uma "avalanche", "inundação", "invasão" ou qualquer outro adjetivo pejorativo no gênero da catástrofe bélica ou ambiental, representam um volume muito pequeno de pessoas, sobretudo se os compararmos com os fluxos de imigrante igualmente irregulares que entram cotidianamente pelos portos, aeroportos e postos de controle de fronteiras. Todavia, são negros e, por tudo que observamos, não há como ignorar o componente da discriminação que, em muitos casos, beira o preconceito e o racismo.

O escritor Tahar Bem Jelloun, em artigo publicado no diário La Repubblica ${ }^{24}$, em 2013, afirma que o racismo é inerente ao ser humano, mas que é preciso, a partir dessa consciência, saber freá-lo. Ele aponta que o racismo está criando raízes na Europa e cita vários episódios - como os xingamentos sofridos pelas ministras de França e Itália e mesmo os que ocorrem com os jogadores negros nos estádios de futebol - enquanto exemplos de manifestações racistas que vão se espraiando pela sociedade. O que se observa na relação com os imigrantes é um forte componente racista, para além de restrições de caráter meramente econômico e de contenção da pressão sobre a prestação de serviços sociais.

Como muito bem observa um imigrante subsaariano, antes eles eram trazidos à força da África para Europa para serem escravizados, como também ocorreu no Brasil. Hoje, simplesmente, utilizam a força para impedi-los de entrar.

A campanha contra o uso do termo "ilegal", lançada recentemente pela Platform for International Cooperationon Undocumented Migrants (PICUM) é uma medida importante para que a questão migratória não seja vista pela ótica da criminalização. Alguns meios de comunicação já estão se comprometendo em eliminar o termo "ilegal" ou indocumentado. O passo seguinte é avançar no

\footnotetext{
${ }^{23}$ BAUMAN, op. cit.

${ }^{24}$ JELLOUN, Tahar B. "O racismo cria raízes na Europa".
} 
sentido de mostrar que não há nada de ilícito em migrar: a mobilidade espacial, ao contrário, é um direito do ser humano.

O desafio é penetrar nos corações e mentes, não só dos detentores do poder, mas também nas sociedades de acolhida, para buscar soluções possíveis para o enfrentamento dessa questão. Soluções podem ser alcançadas e muitas delas já estão presentes nas normas e diretrizes estabelecidas pela Comissão Europeia para o enfrentamento das questões associadas à migração e à concessão de asilo. O que precisa é que saiam do campo da retórica e sejam efetivadas, como por exemplo: i) a mudança do enfoque dado à imigração e aos imigrantes, que deve deixar de ser uma questão de segurança e passar a ser encarada no âmbito dos direitos humanos; ii) o imediato e eficaz combate aos traficantes de pessoas, de forma preventiva e ostensiva; iii) a criação de um fundo de ajuda aos países de origem para estimular investimentos em educação, treinamento profissionalizante, geração de empregos e desenvolvimento econômico, através de um plano de ações controlado pela ONU, de modo a evitar que os recursos sejam desviados de sua finalidade pelos governos corruptos que assolam os países da África, Ásia e América Latina e Caribe; iv) no âmbito desse plano de ações estabelecer um cronograma para o atingimento das metas, paralelamente à diminuição das medidas restritivas e eliminação das barreiras físicas. Isto levando em conta que a medida i) já tenha sido implementada.

\section{Bibliografia}

"Acre sofre com invasão de imigrantes do Haiti". O globo, Rio de Janeiro, 01.01.2012. Disponível em: http://oglobo.globo.com/brasil/acre-sofre-com-invasao-de-imi grantes-do-haiti-3549381. Acesso em: 17.07.2014.

ALVES, Laís A. "Por que o Haiti está aqui?". Outras Mídias, 26.05.2014. Disponível em: http://outraspalavras.net/outrasmidias/capa-outras-midias/por-que-o-haitiesta-aqui/?utm_source $=$ feedly\&utm_reader $=$ feedly\&utm_medium $=$ rss\&utm campaig $n=$ por-que-o-haiti-esta-aqui. Acesso em: 17.07.2014.

ARRUDA, Itaan. "'Caos chegou ao limite', diz secretário do Acre sobre situação de haitianos". Agência Estado, 15.01.2014. Disponível em: <http://www.estadao. com.br/noticias/nacional,caos-chegou-ao-limite-diz-secretario-do-acre-sobresituacao-de-haitianos,1118820,0.htm >. Acesso em: 17.07.2014.

BAUMAN, Zygmunt. Vidas desperdiciadas: La modernidad y sus parias. Barcelona: Paidós, 2013.

BRASIL. Ministério do Trabalho e Emprego, Conselho Nacional de Imigração. Resoluções Normativas. Disponível em: < http://portal.mte.gov.br/trab_estrang/ resolucoes-normativas.htm>. Acesso em: 17.07.2014.

BRASIL. Ministério da Justiça. Conferência de Migrações e Refúgio (COMIGRAR). Disponível em: <http://www.justica.gov.br/noticias/201ccomigrar-deixa-legado- 
de-mobilizacao-e-sensibilizacao201d-diz-secretario-paulo-abrao $>$. Acesso em: 04.06.2014.

BRASIL. Secretaria de Assuntos Estratégicos. Disponível em: < http://www.sae.gov.br/ site/?page_id=19748>. Acesso em: 17.07.2014.

"Brasil: cerrarían frontera con Perú por inmigración haitiana". El comercio, 15.01.2014. Disponível em: <http://elcomercio.pe/mundo/latinoamerica/brasilcerrarian-frontera-peru-inmigracion-haitiana-noticia-1703034 $>$. Acesso em: 17.07.2014.

CASTELLANO, Nicolás. "Não é possível que no século XXI pessoas morram por cruzar uma fronteira". Opera Mundi. 16.03.2014. Disponível em: < http://operamundi. uol.com.br/conteudo/entrevistas/34588/\%E2\%80\%9Cnao + e + possivel + que + no + seculo + xxi + pessoas + morram + por + cruzar + uma + fronteira $\%$ E2\%80\%9D + di z+jornalista +espanhol.shtml>. Acesso em: 17.07.2014.

FERNANDES, Duval; CASTRO, Maria C. G. Migração haitiana ao Brasil: diálogo bilateral. Brasília: Projeto "Estudos sobre a Migração Haitiana ao Brasil e Diálogo Bilateral". Relatório Final, 2014.

GAURIAT, Valérie. "Melilla saltar la valla". EURONEWS. Disponível em: < http:// es.euronews.com/2013/12/09/melilla-saltar-la-valla/>. Acesso em: 17.07.2014.

GOYTISOLO, Juan. "La fuerza del hambre". El país, Madrid, 03.05.2014. Disponível em: <http://politica.elpais.com/politica/2014/05/02/actualidad/1399 048326_216643.html>. Acesso em: 17.07.2014.

GRANJA, João G. "Brasil: algunas pistas para la política migratoria europea". El país, Madrid, 28.10.2013. Disponível em: <http://blogs.elpais.com/3500millones/2013/10/brasil-algunas-pistas-para-la-politica-migratoria-europea. html>. Acesso em: 17.07.2014.

JELLOUN, Tahar B. "O racismo cria raízes na Europa". La Repubblica, Roma, 18.11 .2013. Disponível em: <http://www.voxeuropeu/pt/content/article/4329811-oracismo-cria-raizes-na-europa $>$. Acesso em: 17.07.2014.

JIMÉNEZ, Gemma P. "La Europa enferma: la (des)gestión de la inmigración y el auge del racismo". Passim: Ideas y análisis internacional. 20 oct. 2013. Disponível em: $<$ http://www.passim.eu/la-europa-enferma-la-desgestion-de-la-inmigracion-y-elauge-del-racismo/>. Acesso em: 17.07.2014.

KOSMOPOULOUS, Giorgos. "Las personas migrantes obligadas a probar rutas cada vez más peligrosas". Amnistía Internacional. Disponível em: < https://www. es.amnesty.org/temas/refugio-e-inmigracion/reportajes-especiales/las-personasmigrantes-obligadas-a-probar-rutas-cada-vez-mas-peligrosas/ $>$. Acesso em: 03.07.2014.

MARTINS, José de Souza. "Sem lenço e sem documento". Jornal Estado de São Paulo, São Paulo, 04.05.2014. Disponível em: < http://alias.estadao.com.br/noticias/ geral,sem-lenco-sem-documento-imp-,1162017> . Acesso em: 17.07.2014.

MARTUSCELLI, Patrícia N. "A distância entre Lampedusa e Brasil". 2014. Disponível em: <http://mundorama.net/2014/01/20/a-distancia-entre-lampedusa-e-o-brasil 
-por-patricia-nabuco-martuscelli/> . Acesso em: 03.07.2014.

NARANJO, José. "Empieza el 'camino'”. El país, Madrid, 17.01.2014. Disponível em: <http://elpais.com/elpais/2014/01/10/planeta_futuro/1389360422_513702. html>. Acesso em: 17.07.2014.

ORSI, Carlos. "Ajuda internacional ao Haiti é 'grande mentira', defende tese". Jornal da Unicamp, Campinas, 14-27.04.2014. Disponível em: <http://www.unicamp. br/unicamp/ju/594/ajuda-internacional-ao-haiti-e-grande-mentira-defendetese >. Acesso em: 21.07.2014.

RAMOS, Toñy. "Fernández Díaz dice en Mellilla que a España no se entra por la ventana". El país, Madrid, 24.07.2014.

RECAÑO, Joaquín; DOMINGO, Andreu. Factores sociodemográficos y territoriales de la inmigración irregular en España. Barcelona: Centro de Estudios Demográficos, Universidad de Barcelona, 2004.

REZENDE, Jáder. "Rota é dominada por 'coiotes"”. O tempo, 18.11.2013. Disponível em: <http://www.otempo.com.br/rota-\%C3\%A9-dominada-por-coiotes-1.7476 98>. Acesso em: 17.07.2014.

RODRIGUES, Ronildo. "Haitianos estão entrando no Amazonas pela Venezuela". A crítica. Manaus, 16.01.2014. Disponível em: < http://acritica.uol.com.br/noticias/ Quatros-perspectivas_0_1067293293.html>. Acesso em: 17.07.2014.

SAKAMOTO, Leonardo. "Reclama de haitianos no Brasil e ainda diz que somos todos macacos". UOL Notícias, São Paulo, 29.04.2014. Disponível em: <http:// blogdosakamoto.blogosfera.uol.com.br/2014/04/29/reclama-de-haitianos-nobrasil-e-ainda-diz-que-somos-todos-macacos/>. Acesso em: 17.07.2014.

SÁNCHEZ, Paqui. "Unos 500 inmigrantes acceden a Melilla tras saltar la valla en una de las mayores entradas". El mundo, Madrid, 28.05.2014. Disponível em: http://www.elmundo.es/espana/2014/05/28/53856c10268e3e42098b456c.html. Acesso em: 17.07.2014.

SILVA, Sidney Antonio da. Brazil, a new Eldorado for Immigrants?: The Case of Haitians and the Brazilian Immigration Policy. Urbanities, v. 3, n. 2, November 2013, p. 3-18. "Una tragedia mediterrânea". El país. Disponível em: <http://elpais.com/ elpais/2014/02/25/planeta_futuro/1393344984_448309.html>. Acesso em 08.05.2014.

UNITED NATIONS. World population prospects: the 2012 revison. New York. Disponível em: <http://esa.un.org/wpp/>. Acesso em: 17.07.2014.

VAINER, Carlos. Estado e Migrações no Brasil - anotações para uma história das políticas migratórias. Travessia, São Paulo, v. XIII, n. 36, 2000, p. 15-32.

VALENCIANO, Elena. "Nunca habrá una valla suficientemente alta". El país. Madrid, 02.04.2014. Disponível em: <http://elpais.com/elpais/2014/03/27/ opinion/1395950243_931668.html>. Acesso em: 17.07.2014.

WROBLESKI, Stefano. Imigrantes haitianos são escravizados no Brasil. Repórter Brasil, 23.01.2014. Disponível em: <http://reporterbrasil.org.br/2014/01/imigranteshaitianos-sao-escravizados-no-brasil/> . Acesso em: 17.07.2014. 


\section{Abstract}

\section{The invaders: the threat posed by sub-Saharan migration to Spain} and Haitian migration to Brazil

This article presents the processes that involve the Sub-Saharan migration to Spain and the Haitian to Brazil, through the factors that drive the offsets, the migratory routes used, social inclusion and employment of migrants and the moment of migration policies in each of the countries of destination, highlighting the similarities and some differences in each of these processes. The goal is to show that far from being an invasive threat, most are victims of a system that produces exclusion and exploitation, which in sub-Saharan and Haitians cases are amplifies by components of discrimination and racism.

Keywords: international migration, sub-Saharan emigration, Haitian emigration, discrimination.

Recebido para publicação em 28/08/2014.

Aceito para publicação em 26/11/2014.

Received for publication in August, $28^{\text {th }}, 2014$. Accepted for publication in November, $26^{\text {th }}, 2014$. 